\title{
COVID-19: Schlechter Schlaf im Lockdown
}

Die Universitätsklinik für Psychiatrie und Psychotherapeutische Medizin der Medizinischen Universität Graz beschäftigte sich in einer Studie [1] damit, wie sich das Schlafverhalten bei Menschen mit bipolarer affektiver Störung im ersten harten Lockdown im Frühjahr 2020 und den folgenden Lockerungen im Mai veränderte.

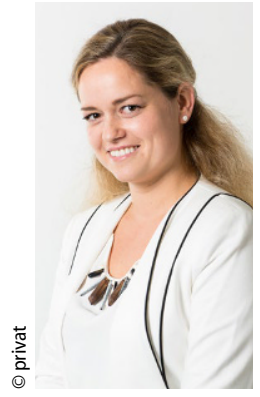

Dr. Frederike Fellendorf, Graz
Viele externe Faktoren können sich auf die Dauer und die Qualität des Schlafes auswirken - einer davon hat jeden betroffen: Die Lockdowns in Folge der SARS-CoV-2-Pandemie. Fast zwei Jahre nach dem ersten Lockdown im Zuge der Corona-Pandemie im März 2020 haben Grazer Wissenschafter*innen einen ersten Einblick darin geliefert, wie sich die Maßnahmen auf unseren Schlaf ausgewirkt haben. Dr. Frederike Fellendorf, Universitätsklinik für Psychiatrie und Psychotherapeutische Medizin, Medizinische Universität Graz, setzte sich mit den Auswirkungen des Lockdowns auf die Schlafqualität von Menschen mit bipolarer affektiver Störung auseinander. Im Rahmen der Studie wurden, um Vergleiche ziehen zu können, Menschen mit einer bipolaren affektiven Störung einer gesunden Kontrollgruppe gegenübergestellt, die jeweils im April und Mai über ihr psychisches Wohlbefinden und ihre Schlafqualität berichteten.

\section{Unruhe in der Pandemie}

Die Studie fand heraus, dass Menschen mit einer bipolaren affektiven Störung sowohl während des ",harten Lockdowns" als auch nach den ersten Lockerungen im Mai 2020 unter einer schlechteren Schlafqualität litten als psychisch gesunde Menschen. Die Gründe, weshalb Menschen mit bipolarer Störung schlechter schlafen konnten, waren vielfältig. Hauptaspekte im Zusammenhang mit schlechtem Schlaf, die sich im Laufe der Studie herauskristallisierten, waren, wie oft sich betroffene Personen über die Entwicklungen rund um Pandemie und das Virus beschäftigten und wie groß die Angst vor dem Virus, einer Ansteckung von sich selbst oder anderen war.
Menschen mit bipolarer Störung beschäftigten sich signifikant häufiger mit neuen Informationen rund um die Geschehnisse und um das Virus als gesunde Menschen. Unter den Studienteilnehmer*innen konnten jene Personen schlechter schlafen, die sich häufiger mit dem Virus beschäftigt hatten. Gleichermaßen stieg die Schlafqualität wieder, als die Pandemie voranschritt und die Informationsfrequenz sukzessive geringer wurde. Insgesamt konnte jedoch durch eine höhere Informationsfrequenz und vermehrte Angst während des harten Lockdowns auch eine schlechtere Schlafqualität für die Zeit der Lockerung vorhergesagt werden.

\section{Relevanz der Erkenntnisse}

„Da die aktuelle Pandemie ein möglicher Trigger für erneute depressive oder manische Krankheitsepisoden darstellen kann, ist es besonders wichtig, auf beeinflussbare Faktoren, wie den Lebensstil, zu achten. Ein gesunder Schlaf ist besonders für Menschen mit bipolarer Erkrankung immens wichtig, auch um weiteren Krankheitsepisoden vorzubeugen“, so Fellendorf. Mit den Ergebnissen dieser Studie appellieren die Forscher*innen für einen verantwortungsvollen Umgang mit Informationen über die aktuelle Pandemie, vor allem an Menschen, die zu besonders anfälligen Gruppen gehören wie eben bipolar Erkrankte. „Zudem sollte in der psychosozialen Behandlung auf spezifische Ängste eingegangen werden, um Personen mit bipolarer Erkrankung zu unterstützen und ebenso auch den Schlaf positiv zu beeinflussen", so Fellendorf.

\section{Literatur}

1. https://www.ncbi.nlm.nih.gov/pmc/articles/ PMC8420206/

Hinweis des Verlags. Der Verlag bleibt in Hinblick auf geografische Zuordnungen und Gebietsbezeichnungen in veröffentlichten Karten und Institutsadressen neutral.

psychopraxis. neuropraxis $2022 \cdot 25: 12-13$ https://doi.org/10.1007/s00739-022-

00781-0

(C) The Author(s), under exclusive licence to Springer-Verlag GmbH Austria, ein Teil von Springer Nature 2022

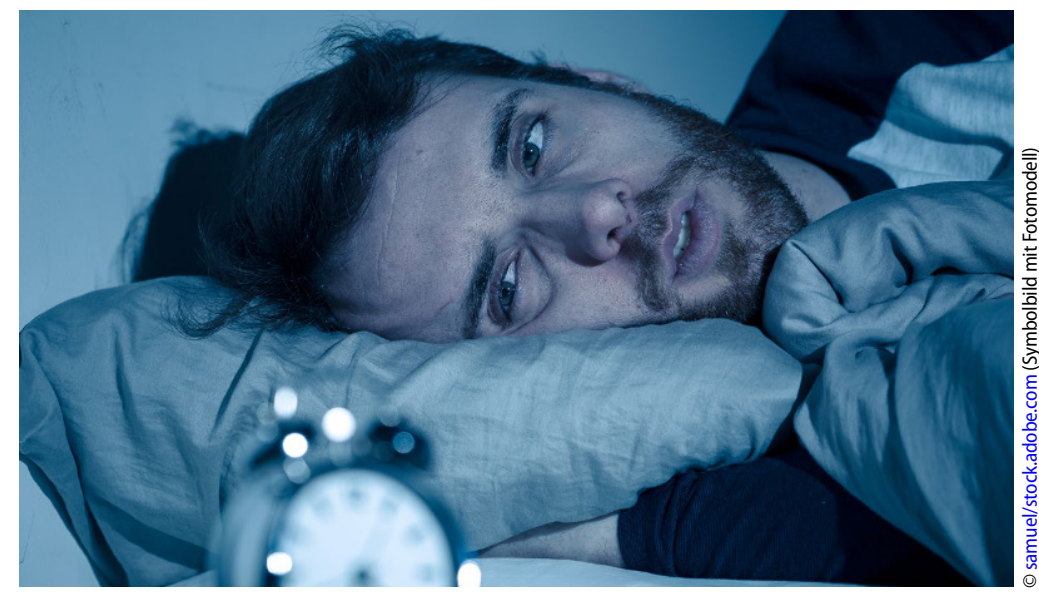

$\Delta$ Menschen mit einer bipolaren affektiven Störung litten sowohl während des „harten Lockdowns" als auch nach den ersten Lockerungen im Mai 2020 unter einer schlechteren Schlafqualität 
Hier steht eine Anzeige.

Springer 